\title{
Employees' Perception of a Community College Dimensions as Learning Organization and Readiness to Change
}

\author{
MARICELLE MERCADER-NUEVA \\ ORCID No. 0000-0003-1110-5468 \\ maricellenueva@gmail.com \\ Gov. Alfonso D. Tan College \\ Tangub City, Philippines
}

\begin{abstract}
Learning organizations are found to be more resilient and adaptive to globalized pressure. For a Community College that vows to serve quality education, it also needs to pursue how it can cope with the rapidly changing environment demanded by globalization. This study aimed to assess the dimensions of learning organization at a Community College and its readiness to change. This study utilized the mixed method integrating quantitative and qualitative approach. The researcher used the survey method consisted of a demographic questionnaire, the DLOQ (Watkins \& Marsick, 1993, 1996, 1999) instrument, and attitude toward change instrument by Dunham et al. (1989). The study revealed that demographics like age, educational attainment, employment status and years of experience are a significant source of differentiating opinions among the respondents considering the seven dimensions of the learning organization. Learning organization as a paradigm should be approached holistically. It is of paramount importance that the community college values its faculty and staff, regarding them as the most important resource to gain competitive advantage and to meet the demands of globalized pressure.
\end{abstract}

Keywords: Learning organization, readiness to change, demographics

\section{INTRODUCTION}

Learning is the key to future success and the foundation to adapt to the rapid change successfully both for individuals and for organizations. Learning organization is a widely known concept for many organizations, both entrepreneurial and academic. It is considered as one of the key foundations to 
adapt to the world of changes especially in this era of globalization. This globalized pressure is perceived as forces acting on educational institutions that are tied to culture, economics, politics, business, and power "pushing 21st century higher education toward greater international involvement" (Altbach and Knight, 2007; Bond, 2006 as cited by Cinches, Russell, Chavez and Borbon, 2015).

Many educational leaders find difficulty in responding quickly and flexibly to the increasing expectations of these unpredictable changing environments. Many believe that to overcome today's difficulties in education systems, adapting the learning organization posture is still the best means of coping with the globalized pressure for change (Ayupp and Perumal, 2008; Moloi et al., 2009; Senge, 2006).

Peter Senge (1990) describes a learning organization as one that connects its members closely to the mission, goals, and challenges of the organization. His theory asserts that these close connections are necessary for the organization to meet the demands of rapid change. Thus, the need for such organization is to be flexible and adaptive to rapid change to become truly productive and successful. For this to happen, it is argued, that organization need to 'discover how to tap people's commitment and capacity to learn at all levels (Senge, 1990). This applies to both individuals and organizations. Thus, for a learning organization, it is not enough to survive, it needs to be dynamic enough to empower employees to be creative, productive in many ways. Learning in organizations with the purpose of making employees feel empowered has been shown to be a significant factor in organizational successfulness, and in adaptation to changes, helping organizations to survive longer than their counterparts (Asadi, Ghorbani, and Naderan, 2009; Dirani, 2009; Marsick, 2009; Watkins and Marsick, 2003).

In almost twenty (20) years of working in a community college, this researcher observed and experienced different issues and concerns regarding the organization's manner of responding to change especially those that are brought about by globalized pressure. On top of these are funding and governance issues. Unprofessionalism and the poor control and management of conflicts have become common to the everyday life in the college. These conflicts usually occur among faculty and department heads of the college. Senge (1990) explained that these could arise in large part from differences in values, beliefs, and attitudes regarding varied issues. It is believed that unmanaged conflict is a threat to the survival of the organization and, at the least, tends to make it less effective (Senge, 1990).

With the demands of the recent reforms in the Philippine educational system, the community college is faced among all others, with the dilemma of responding 
to the need for more qualified teachers. It is necessary for the community college to upgrade teachers so that they can adequately cope with these crucial mandates. Allied with these issues and concerns are leadership and management training concerns. Due to the scarcity of funds in the local government, training, seminars, conferences, benchmarking and other faculty and staff development were limited since the community college is very dependent on the measly budget allocated by the LGU for this. Anent to this concern is also the standardization of salary to be competitive. Unmotivated faculty and staff stay for a while and eventually go elsewhere. Most of them transferred to the Department of Education (DepEd); some applied for Non-Uniformed Personnel positions in the Philippine National Police.

Work overload and too much multitasking are also issues confronting this community college in a review. Many of the faculty and staff with little and even with no experience and advanced studies were left with no choice when they found themselves designated to top level positions and other positions in the college and even in the Local Government Unit.

This writer's experience is a case in point. From a computer science faculty of 18 years, this researcher was designated as the Assistant College Administrator for External Affairs for the last two (2) years up to the present and at the same time also appointed as the Local Economic and Investment Promotion Officer in the LGU. Added to this, are designations to head various committees when there are College's and LGU's activities. Though thankful for the trust and confidence, this researcher loses focus more often than not especially with regards to priorities. The much-needed productivity and quality of work have been sacrificed to a great extent due to excessive demands of multitasking.

What complicates the situation is that most of the academic personnel of this community college have very low awareness of the standards of excellence as seen by reports and outcomes of the institution. Qualification of teachers, some facilities of the institutions and instructional materials and strategies do not conform to accreditation standards. At present even at Level 1, none of the programs have passed the standards; none of the programs have been awarded accreditation status.

Situations such as these can weaken organizations when not adequately addressed. Crippling learning disabilities have been with the community college for thirty years since its existence. Senge (1990) stressed that "learning disabilities are tragic to children, but they are fatal in organizations." He further argued that what is needed is a systems approach that focuses shifts to shared responsibility 
and pro-activity. This argument continues to be among the major motivations of this researcher to pursue and sustain the momentum of this present study. It is good to determine to what extent is the community college likely to develop into a learning organization; this may give the institution the initial head start to proceed from the present status quo.

In educational settings, few types of research can be found to show the application of a learning organization (Tseng, 2010; Wang, 2007). Studies relating to learning organization are not well represented in education sector which is expected to play a key role in preparing future leaders (Bui \& Baruch, 2010).

With the present issues and concerns confronting this community college, this study used the learning organization model within the given educational contexts. Given the above situation and justifications, this study was conceptualized with so much optimism that every problem has a solution. This investigation hopes to offer alternative ways of doing things that would direct the whole community college system toward a collective effort of bringing the institution into greater heights of the standard. Through this, it serves the promised quality education pledged in its vision and mission statements.

\section{FRAMEWORK}

The theoretical framework of this study included Peter Senge's popular concept of learning organization with his work "The Fifth Discipline: The Art and Practice of the Learning Organization”; Watkins and Marsick's (1993, 1996, 1999) Dimensions of Learning Organization and Perceived Organizational Readiness for Change denoted by the Attitude Toward Change framework of Dunham et al. (1989) and the famous and widely accepted Change Theory of Kurt Lewin (1951). It is strongly believed that these principles would help establish a strong foundation of this study.

Perhaps the most comprehensive description of a learning organization is presented by Peter Senge (2006):

\section{A learning organization is where people unceasingly develop their capability to create the results they truly aspire, where new and expansive patterns of thinking are fostered, and where people are persistently learning together Senge (2006).}


He further pointed out five key learning areas which he called as "The Five Disciplines." These are Personal Mastery, Mental Models, Systems Thinking, Shared Vision and Team Learning.

It is however argued that there is no instant and perfect formula. Various institutions vary in their ways, processes, procedures, strategies and systems to learn for change. However, this change goes beyond organization's life ways. There are significant elements that all learning organizations have to go through.

Senge proposes that people put aside their old ways of thinking (Mental Models), learn to be open with others (Personal Mastery), understand how their company really works (Systems Thinking), form a plan everyone can agree (Shared Vision), and then work together to achieve that vision (Team Learning). Each discipline is made up of guiding ideas, tools and techniques, and practices. According to Senge, these Five Disciplines must be methodically cultivated by leaders in learning organization to thrive on change and constantly innovate.

All the five (5) Disciplines are interconnected in nature and work together to create a learning organization. Learning organization has its profound impact on employees' development both in skill and personal life; many organizations in different parts of the world have preferred to adapt to learning organization (Alam, 2009; Jamali and Yusuf, 2009). This model advocates that organizations' main focus should be on innovation, not just problem-solving, which requires a highly collaborative and creative organizational paradigm. The learning organization embodies this model. Top-level managers have realized that to increase efficiency, improve customer service, and achieve organizational objectives, learning organization is the best choice (Ayupp and Perumal, 2008; Jamali and Yusuf, 2009; Watkins and Marsick, 1993).

Learning organization however, still calls for further study despite of its benefits and wide acceptance. The main reason is that most researches in the past have been done in business companies (Senge, 2006). Research efforts on learning organizations are directed primarily at assessing businesses and industrial organizations (Patnaik, Beriha, Mahapatra, and Singh, 2012). Financial performance and/or knowledge performance were the focus in most studies relating to learning organization (Al-Jawazneh and Al-Awawdeh, 2011; Filstad and Gottschalk, 2011; Jamali et al., 2009; Kumar and Idris, 2006; Lien et al., 2002; McHargue, 2003).

Learning organization constructs were also identified by seven indicators, or dimensions, from Watkins and Marsick $(1993,1996,1999)$ which were based on Peter Senge's model, and these are: 
Create continuous learning opportunities, promote inquiry and dialogue, encourage collaboration and team learning, create systems to capture and share learning, empower people toward a collective vision, connect the organization to its environment, and provide strategic leadership for learning (Watkins et al., 1993, 1996, 1999).

The model of Watkins et al. (1993) called the "Seven Dimensions of a Learning Organization" is aligned with Peter Senge's "Five Learning Disciplines." Like Senge (1990), their theory is based on team-building, in which the organization's capacity for innovation and growth is constantly enhanced, leading to continuous growth and transformation. Senge's (1990) first three disciplines of individual learning is also emphasized in Watkins' et al. (1993) continuous learning and promotion of inquiry and dialogue. The other five dimensions: encouraging collaboration and team learning, systems learning, empowerment, connecting the organization to its environment, and strategic leadership are depicted in the last two disciplines of Senge (1900) which dealt with group learning.

This model explained that "Learning organizations are described by complete employee envelopment in a manner of collaboratively conducted, cooperatively responsible change directed towards shared values or principles." In a learning organization, the emphasis on the need for collective learning throughout the system can lead to overall organizational change if properly communicated to all members of the organization.

Finally, Senge (1990) and Watkins et al. (1993) viewed learning organization as one that can integrate people and structures to move towards continuous learning and change.

Academicians and practitioners are in agreement that change is a constant feature of organizational life. Change is a common thread that runs through all institutions regardless of size, industry and age. For organizations existing in these times, life can be extremely challenging. The world is changing fast and, as such, organizations must change quickly too. Organizations that handle change well prosper, at the same time those that do not may struggle to survive (Causon, 2004; Staniforth, 1996).

Many organizations found change to be a real challenge. Even though there are no official numbers, researchers estimate that at least two-thirds of the change initiatives fail (Choi, 2011). Research from the last decades suggests that most of these change projects fail due to the underestimation of the central role that individuals play in this process (Greenhalgh, Robert, MacFarlane, Bate, and 
Kyriakidou, 2004). It is worthwhile to note that employees of the organization play crucial roles in any change effort because the change is often targeted at them. For these employees, however, organizational change can be distressing and can cause conflicts of interest or feelings of insecurity as well as loss of control. These feelings eventually may lead to stress, a decrease in job satisfaction or resistance (Greenwood and Hinnings, 1996; Brown and Cregan, 2008; McConnell, 2010).

Furthermore, the risk of failure is greater since people are generally resistant to changes. For some, change may bring satisfaction, joy, and advantages, while for others the same change may bring pain, stress and disadvantages. These undesired effects should not be underestimated since employees can solely determine the success or failure of an organizational change process (Yousef, 2000). Consequently, individual attitudes towards change play a significant role in the successful completion of an organizational change process (Giessner, 2011).

Many studies found that the contributory factor deterrent to change is resistance and instead of attempting to resist the resistance, change agents must take the proactive approach to managing it. A study of Haque (2008) reported that resistance is frequently linked with negative attitudes, and often resistance is less recognized but critically significant contributor to the higher rate of failure of change. Further, the said study reported that famous studies in the past proposed that instead of dealing with the complexities associated with the resistance to change, organizations can and should avoid it by creating a state of readiness for change.

Peach, Jimmieson, and White (2005) defined readiness for change as, "the extent to which people embrace constructive views about the need for change, as well as the degree to which people consider that such changes are expected to have constructive implications for themselves and the wider association."

This study theorizes that the organization's readiness for change is found where a learning organization thrives. One of the cornerstone models for understanding organizational change was developed by Kurt Lewin back in the 1950s, and still holds true today. This pioneer theorist of organizational change suggested that change is a process involving three stages: unfreezing, changing and refreezing.

Readiness for change. An individual's perception of an organization's readiness for change is viewed as a similar concept to unfreezing (Bernerth, 2004; Madsen et al., 2005; Miller et al., 2006; Rafferty and Simons, 2006). This is described as a process in which an individual's beliefs and attitudes about pending change are influenced such that the imminent change is seen as useful (Lewin, 1951). Lewin 
indicated that the unfreezing stage motivates replacement of the old learning with new, thereby hinting at the relationship between learning and readiness for change.

Dunham, Grube, Gardner, Cummings and Pierce, J. (1989) said that among the manifestations of the readiness to change include positive attitudes such as viewing change as beneficial to the organization and to the employees and looking forward to changing in their workplace as well as finding change as a pleasing exercise. On the other hand, resistance to change can occur when employees resist new ideas and find change as frustrating and tend not to cooperate with change endeavors (Dunham et al., 1989).

Demographics. Within the professional arena and across disciplines, there has been evidence of a thirst for more knowledge related to learning organizations (Egan, Yang, and Bartlett, 2004; Song, Joo, and Chermack, 2009; Wang, Yang, and McLean, 2007). However, emphasis on the study related to learning organization has been placed on cultural influence and learning organization, motivation, culture and commitment, leadership style, and quality of work. There are limited studies though in the field of learning organizations that examine organizational demographic composition as an influential factor in employees' perception of their organization as a learning organization.

Johnson (2015), in his study on "Do Age and Education Matter? Organizational Demography as an Influential Factor on Perceptions of a Learning Organization in Law Enforcement" revealed that the officers' perceptions of the organization as promoting learning practices and cultures are neutral, revealing significant differences in their perceptions related to educational level.

On the other hand, employee demographic characteristics (i.e. present employee status) were considered to be predictive factors of employee readiness for organizational change (Shah et al., 2004). In the study of Shah et al., (2004) entitled "Relationships between employee readiness for organizational change, supervisor and peer relations and demography," found out that younger employees are more ready for and open to organizational change than older employees. These relations highlight the need to consider these factors within policy and strategy to promote employee openness to and readiness for organizational change. Numerous factors affect employee satisfaction and motivation such as job characteristics, employee's behavior, personal value system and other demographic and organizational factors (Gil et al., 2008). Acuna with a group of researchers said that personal characteristics of the employees, or the term demographic data, enable the formation of a valid and reliable instrument for 
measuring motivation and satisfaction (Acuna et al., 2009). Likewise, several factors have shown to be good predictors of organizational commitment. Some of these factors that have been considered include personality traits, demographic characteristics (Azeem, 2010; Brimeyer, Perrucci, \& Wads-worth, 2010).

In fine, this study theorized that the employees' perception of a community college dimensions of a learning organization and readiness to change differed based on their demographics.

\section{OBJECTIVES OF THE STUDY}

This study aimed to assess the dimensions of learning organization at a Community College and its readiness to change. Specifically, it had two specific directions, namely: (1) The extent of respondents' perception of the community college as a learning organization in terms of: continuous learning; inquiry and dialogue; collaboration and team learning; embedded systems learning; empowerment; system connection; and strategic leadership. (2) Differences among employees in their assessment of the community college as learning organization and its readiness to change based on their age, gender, highest educational attainment, job responsibility, the level of employment, and years of experience.

\section{METHODOLOGY}

The study utilized the mixed method to assess the dimensions of learning organization at a Community College and its readiness to change. Mixed method is a methodology for conducting research that involves collecting, analyzing, and integrating (or mixing) quantitative and qualitative research (and data) in a single study or a longitudinal program of inquiry (Creswell, 2009).

In this study, the dimensions of a learning organization and readiness to change of the organization were assessed using quantitative data. To strengthen the rigor, enrich the analysis, and ensure those study findings are grounded in participants' experiences, the qualitative approach like interviews and or observations or other necessary approaches were employed. These measures enriched and deepened the findings of the study.

All 136 full- time employees regardless of their highest educational attainment, age and gender were considered as respondents of the study. The respondents of the study were called, gathered, oriented on the purpose of the study and were 
likewise briefed on the content of the instruments. This was done in two batches on two separate dates. The staffs were gathered first followed by the faculty on the next day. Consent was obtained from the respondents to conduct the research with confidentiality and that their participation is voluntary in nature.

\section{RESULTS AND DISCUSSION}

\section{Objective 1. The extent of respondents' perception of the community college as a learning in terms of continuous learning; inquiry and dialogue; collaboration and team learning; embedded systems learning; empowerment; system connection; and strategic leadership}

Descriptive presentation of responses and indicators in each dimension are shown below.

Continuous Learning. The overall mean score of 3.24 meaning occasionally implies that people in the organization show an irregularity in the desire of learning of new skills and supporting it. This is supported by the frequency data that almost $89 \%$ of the respondents answered only from sometimes to never. This finding suggests that this continuous learning organization dimension is not so favorably supported. Only more than $11 \%$ of the respondents answered always and frequently.

The data further disclosed that the respondents perceived people in the organization were 'rarely' $(\mathrm{M}=2.41)$ given the resources to support their learning, meaning they have unfavorable perception of this statement. They also viewed "people openly discuss mistakes in order to learn from them" (M=3.00, occasionally). Likewise, respondents also assessed the indicator "people in their organization view problems in their work as an opportunity to learn" with a mean of 3.24, also interpreted as occasionally which further imply of the 'not so favorable' view of the respondents on continuous learning.

On the other hand, the statement: "except people in my organization help each other learn" ( $\mathrm{M}=3.75$, sometimes) 'favorably' impressed the respondents. Some people in this community college were perceived by the respondents as openminded to a certain extend; they considered other's deficiencies and manifested generosity to help others learn and improve their craft. The limited funding of the Local Government Unit is one of the causes of not giving cash incentives. However, recognition of the faculty who finished their graduate studies had 
been given by the Faculty and Staff Association of the College. This practice is appreciated by most if not all respondents.

In the Focus Group Discussion (FGD) conducted, these survey findings were validated by the following statements of the respondents:

1. "wala kaayo'y support sa pag skwela namo uy, usahay naay deloading of 6 units"; "we were rarely supported by the Administration in pursuing graduate studies, sometimes employees' pursuing graduate studies were deloaded of 6 units"

2. "maski seminars ug trainings talagsa ra kaayo, pipila ra ang maka attend kay sige lang walay budget kulang ang budget"; "only very few employees were rarely sent to seminars and other faculty development activities due to budgetary constraints and funding deficiencies"

3. "kasagara sa mga faculty nga ninglampos,ilaha rang kaugalingong kuarta ang gigasto, ug diskarte gyud ka pra dili ma deprive ang mga students sa klase" ; Most of the faculty who had finished their graduate degrees spent their own money and wisely allocated their time so as not to deprive quality service to their students" (February 15, 2016 10:00 a.m.)

Watkins et al., (1996) theorized that continuous learning opportunity means learning becomes an everyday part of the job and is built into routine tasks; employees are expected to learn not only skills relating to their own jobs but also the skills of others in their work unit and how their work unit relates to the operation and goals of the business; employees are expected to teach, as well as learn from their co-workers. In short, the entire work environment is geared towards the learning of new skills and supporting it (Watkins et al., 1993). In this present study, this dimension of a learning organization is only not so favorably felt by the employees. There is a need for the institution to create a necessary environment in order for the organization to inspire the "entire work environment towards the learning of new skills and supporting it."

Promote Inquiry and Dialogue. This dimension was assessed with an overall mean of 3.32, described as occasionally. Similar to the trend of the responses on the previous dimension, the bulk of responses or $88 \%$ of the respondents' answers ranged from sometimes to never. Only $12 \%$ of the respondents found this learning organization dimension 'very highly favorable' to 'highly favorable' since only 
16 employees answered always and frequently. Moreover, items such as "In my organization, people are encouraged to ask "why" regardless of rank were described as occasionally with mean $2.83(\mathrm{SD}=1.404) 2.92(\mathrm{SD}=1.48)$, respectively which are also interpreted as 'not so favorable'. There were only two indicators that were rated as 'favorable' and the rest of the items were 'not so favorable.'

Furthermore, the Focus Group Discussions result disclosed that "sometimes a more liberal and open social atmosphere air have been felt among members of the same level or status." However, "it is very hard for employees to defend or express their sides in times of controversies since the line of communication between the top authorities and subordinates are observed by the employees to be limitedly open". A permanent faculty of nine (9) years in the college expressed "that dialogue and inquiry are only occasionally felt in the college since the organization is an agency of the Local Government Unit (LGU). Thus, it cannot be avoided that people take action politically according to the whims of the incumbent political leaders/administrators" (February 15, 2016, 10:00 a.m.).

Furthermore, the Focus Group Discussions result disclosed that "sometimes a more liberal and open social atmosphere air have been felt among members of the same level or status." However, "it is very hard for employees to defend or express their sides in times of controversies since the line of communication between the top authorities and subordinates are observed by the employees to be limitedly open". A permanent faculty of nine (9) years in the college expressed "that dialogue and inquiry are only occasionally felt in the college since the organization is an agency of the Local Government Unit (LGU). Thus, it cannot be avoided that people take action politically according to the whims of the incumbent political leaders/administrators" (February 15, 2016, 10:00 a.m.)

In a learning organization, according to Watkins et al., (1993), employees would gain creative reasoning skills to express their opinions, views, and the ability to listen and to make inquiries into the views of others; the culture of the learning organization that supports inquiry, feedback, and experimentation was found to be nearly nonexistent in the community college.

The findings generally revealed that the community college as an organization need to strive more to allow consciously people to explore the ideas and question potential actions. It is important that a culture of open-mindedness and encouraging curiosity should be nurtured by suspending presuppositions and judgments in the interests of truth for better solutions (Watkins et al., 1993). 
Encourage Collaboration and Team Learning. Data revealed that this dimension is favorably rated by the respondents considering that the overall mean of 3.57 is interpreted as 'sometimes' compared to the 'occasionally' response on the previous two dimensions: 'continuous learning' and 'dialogue and inquiry.' The majority of $55 \%$ of the respondents answered from 'always' to 'sometimes.' A lesser percent of 45 answered from 'occasionally' to 'never.'

Moreover, "In my organization, teams/groups treat members as equals, regardless of rank, culture, or other differences" $(\mathrm{M}=3.89)$ was the highest rated indicator although it denoted only 'sometimes'. They also viewed "In my organization, teams/groups focus both on the group's task and on how well the group is working" ( $\mathrm{M}=3.77$, sometimes). Likewise, items such as "In my organization, teams/groups revise their thinking as a result of the group discussion or information collected" and "In my organization, teams/groups have the freedom to adapt their goals as needed" were described as sometimes with mean 3.67 and 3.60, respectively.

This means that employees perceived collaboration and team learning more 'favorably' compared to the two previous dimensions. Work is considered to use groups to access diverse approaches of discerning, and these groups are likely to learn and work together. Therefore, collaboration is valued by the organizational culture (Watkins et al., 1993).

Results of the Focus Group Discussion (FGD) however, revealed that team learning indicators that are less displayed in the college were the granting of rewards and organization acting on team's recommendation. This was supported by the following statements:

1. "na observe nako nga adunay pagtinabangay labi na kun naay mga activities or program sa college", "I observed that people in the college are helping one another especially when there are college programs and activities"

2. "gamay ra ang na assign sa team nga mo work ug dli kaayo mapaminaw ang suggestions and if mo succeed, maski thank you ug congrats seldom ra kaayo madungog sa team" "only few are chosen to perform a task and then suggestions were seldom carried, and if the task is successfully done, the team felt no recognition and appreciation" (February 15, 2016, 10:00a.m.)

In this present study, this dimension of a learning organization is generally favorably felt. Furthermore, the findings revealed that people in the organization 
collaborate each other.

It is vital that a culture of team learning should be strengthened because "teams, not individuals, are the fundamental learning unit in modern organizations. Unless teams can learn, an organization cannot learn” (Senge, 1990).

Embedded Systems Learning. This dimension was assessed with an overall mean score of 3.20 described as occasionally. This is supported by the frequency data that more than $84 \%$ of the respondents answered only from sometimes to never. There were less respondents or almost $16 \%$ answered 'always' to 'frequently.'

Although the general finding suggests that embedded systems learning dimension were generally occasionally perceived meaning 'not so favorably' supported, the item: "My organization creates systems to measure gaps between current and expected performance", was observed to be 'favorably' felt in the college.

Nevertheless, the respondents perceived the community college as only 'occasionally' which means 'not so favorable' maintenance of an up-to-date database of employee skills. They also rated "My organization measures the results of the time and resources spent on training" ( $\mathrm{M}=3.00$, occasionally) also "not so favorable'. Likewise, respondents also assessed the item "My organization uses twoway communication on a regular basis, such as suggestion systems, electronic bulletin boards, or town hall/open meetings" with a mean of 3.03, also as occasionally. This dimension of embedded systems learning, was observed to be 'not so favorable' by the employees.

Furthermore, the Focus Group Discussion results validated that "trainings were seldom conducted, and if ever there were, these were just taken for granted, because after the seminar no more follow-up activities or reports." Respondents also claimed that "no up to date data maintained if there are any, only very occasionally and communication systems like suggestion system and open meetings were seldom conducted' (February 15, 2016, 3:00 p.m.).

Watkins et al., (1996) theorized that for this dimension, high and low technology systems for sharing learning are generated and assimilated in the work. In this present study, embedded learning systems to capture and share learning dimension was, occasionally or 'not so favorably' felt. Thus, there is a 
need for the institution to provide access and system maintenance to be able to get information quickly and make its lesson learned available to employees (Watkins et al., 1996).

Empower People Toward a Collective Vision. This dimension was assessed with an overall mean of 3.16 , described as occasionally. ( $\mathrm{SD}=1.445)$, respectively. Only one indicator was rated sometimes, and the rest were occasionally.

Moreover, items such as "My organization gives people choices in their work assignments", "My organization recognizes people for taking initiative", "My organization invites people to contribute to the organization's vision" and "My organization gives people control over the resources they need to accomplish their work" were described as occasionally with mean 2.59 ( $\mathrm{SD}=1.365), 3.06(\mathrm{SD}=1.526)$, $3.31(\mathrm{SD}=1.298)$ and 3.34. Similar to the preceding dimension, more than $90 \%$ of the respondents' answers ranged from sometimes to never.

In the Focus Group Discussion (FGD) conducted, these survey findings were validated by the following statements of the respondents:

1. "pipila ra ang faculty or staff mag work ug naay assignment, kasagara balik balik ra ang team ang sugoon ang kadaghanan, wala", (Only few were given assignments, usually the same group of people were given work assignments)

2. "Surprise kasagara ang atong membership sa committee ug work assignments, no choice." (People are left with no choice as to membership to committee and work assignments)

3. "motrabaho unta ta pero wala or kulang ang materials and resources, kita pay mangita ug modiskarte para mahuman ang trabaho" (as much as we want to work, the resources are not enough, we have to find our own just to finish the task.)

4. "nanginahanglan pod tag appreciation after work accomplishments bya pero maski pikpik sa likod sa mga tigsugo lang gud ok naa unta pero wala," "we all need even a tap in the back after accomplishing a task" (February 15, 2016, 3:00 p.m.)

Watkins et al., (1996) said that in a learning organization, people are involved in setting, owning and implementing a joint vision. It depends on the 
participation of many individuals in a collective vision and on the release of the potential that are often locked within them because opportunities are not created. In this present study, this empowerment dimension of learning organization is perceived by the respondents as sometimes and occasionally felt in the college. Generally, then, the community college in this study was found to be 'not so favorably' supporting the learning organization dimension of empowerment. Thus, there is a need to distribute responsibility to motivate people to learn what they are accountable for and for the institution to begin with a shared vision so that learning is directed toward that vision (Watkins et al., 1996).

System Connection. The overall mean score of 3.38 meaning occasionally indicates that the academic organization was found to show their concerns with their physical, social and cultural environments to a limited extent. The frequency data that almost $80 \%$ of the respondents answered from sometimes to never. This finding suggests that this system connection dimension is 'not so favorably' felt in the institution. Only more than $20 \%$ of the employees felt that this learning organization dimension is either 'very highly favorable' or 'highly favorable'.

The data further reveals that "My organization encourages everyone to bring the clients' views into the decision-making process" and "My organization encourages people to get answers from across the organization when solving problems" were described as occasionally $(\mathrm{M}=3.17, \mathrm{SD}-1.412)$ and $(\mathrm{M}=3.19, \mathrm{SD}=1.442)$, respectively. There were only two indicators viewed as sometimes, and the rest were seen as occasionally practiced.

Additionally, results of the Focus Group Discussion (FGD) validated the survey findings "soliciting people's view and suggestions from the outside is uncommon". On the other hand, respondents claimed that "organization tried to balance the work and family life of employees" (February 15, 6:00 p.m.).

According to Watkins and Marsick (1993), learning organizations manifest healthy relationship with their physical, social and cultural environments. The learning organization acknowledges its dependence on its environment and must continuously interact with the community. In effect, learning organization helps employees balance work and family. In this present study, this dimension of a learning organization is only 'not so favorably experienced by the community college employees. This institution in focus need to look into their policies and in terms of encouraging employees to think globally and to get answers from 
across the organization when solving a problem (Watkins et al., 1993).

Provide Strategic Leadership for Learning. The data reveals that this dimension was 'not so favorably' rated by the respondents considering that the overall mean of 3.35 implies 'occasionally.' Majority or $76 \%$ of the respondents answered from sometimes to never. A lesser number (24\%) on the other hand, answered from always to frequently. The table further disclosed that the respondents perceived leaders in the organization 'not so favorably' $(M=3.17$, occasionally) share up to date information with employees about competitors, industry trends, and organizational directions.

They also viewed "In my organization, leaders mentor and coach those they lead" with a mean of 3.26, as occasionally. Likewise, respondents also assessed the indicator "In my organization, leaders support requests for learning opportunities and training" with a mean of 3.35, as occasionally. However, there were situations when respondents experienced the perceived leadership 'favorably' in the organization where leaders sometimes "ensure that the organization's actions are consistent with its values." In the FGD that transpired (February 15, 2016, 6:00 p.m.), result disclosed following statements:

1. "there is no regular meeting among faculty and staff, the information is just limited to some people."

2. "rarely heads in the college mentor us."

3. "rarely leaders look for opportunities for us, faculty and staff"

4. "dugay mopagawas ug budget labi na sa training, if naay budget dugay ang processing", "budget is limited and takes so much time to process."

The presence of strategic leadership in the community college as validated in the FGD was 'not so favorably' rated by the respondents. In a learning organization, leaders do mentor and coaching and they give up to date information about organizational directions and industry trends as a matter of practice. The findings revealed that leaders in the community college as an organization need to model, champion and support learning. It is also important that leaders ensure that organizations actions are consistent with its values (Watkins et al., 1993). 
Finally, Senge (1990) and Watkins \& Marsick (1993) viewed learning organization as one that can integrate people and structures in order to move towards continuous learning and change. Of all dimensions of a learning organization, only collaboration and team learning was found to be favorably felt by the respondents. The six dimensions of learning organization which were perceived as 'not so favorably' felt by the respondents send a strong signal to the community college how it had fallen short of the learning organization standards. The overall average mean is 3.31 , described as occasionally imply that in the present study, dimensions of a learning organization as perceived by the respondents are not so favorably supported.

Objective 2. Differences among employees in their assessment of the community college as learning organization and its readiness to change based on their age, gender, highest educational attainment, job responsibility, the level of employment, and years of experience

For the dimensions of a learning organization, only dialogue and inquiry showed a significant variation of responses within age groups with F-value of 4.21 and sig. level of .007 . The hypothesis of no significant difference between dialogue and inquiry is rejected. Age is a source of variation of perceptions of respondents on dialogue and inquiry as a dimension of a learning organization.

The result indicates that dialogue and inquiry were rated by the younger employees higher $(\mathrm{M}=3.86$, sometimes $)$ observed this dimension more 'favorably' compared to the older ones who answered occasionally. It is usually the attitude of young employees to be vocal and or inquisitive about the policies of the organization. In fact, during the Focused Group Discussion, the respondents confirmed that the young faculty members in the community college have fewer inhibitions in conveying their confusions to any of the members of the administration. However, to the older ones, dialogue and inquiry are only occasionally felt and happens only during meetings. Nevertheless, "when issues are about administration's decision, things are better left unsaid" (February 15, 2016, 6:00 p.m.).

This means that among the learning organization dimensions variables considering age, only the dialogue and inquiry dimension most likely occurred positively among the younger ones. In an educational institution, older and more 
experienced teachers express significantly less satisfaction with their professional role than their younger and less experienced colleagues (Perichione et al., 2008 as cited by Saavedra, 2010). On the whole, age is a differentiating factor in this learning organization dimension and specifically on dialogue and inquiry.

On the other hand, no significant difference was found among the different age brackets in terms of other the learning organization variables as well as on attitude towards readiness to change. The hypothesis is not rejected in these cases. Perceptions of the respondents on the other six dimensions do not vary significantly when the respondents were grouped according to their ages.

The data show results of the tests of difference between male and female on dimensions of a learning organization and their readiness/attitude to change using student's t-test. The respondents' perception of the dimensions of learning organization as well as the readiness to change attitude were found to have no significant variations when they were grouped according to gender. The hypothesis is not rejected. This means that regardless of gender, the respondents have more or less comparable view about the community college as learning organization as well as in their readiness to change attitude.

The statistical test shows that there are significant differences in their responses in continuous learning, dialogue and inquiry and embedded system. The null hypothesis is rejected in these dimensions of a learning organization. In the data, age was also a differentiating factor in dialogue and inquiry dimension.

This is further reinforced by the findings that those who have lower educational attainment have higher mean scores that contributed to the significant difference compared to those who have higher educational attainment. The one with lower educational attainment belonged to the younger batches of the respondents. Furthermore, in embedded systems this referred to "high and low technology systems for sharing learning that are created and integrated into the work; access is provided and systems are maintained" according to Watkins et al., (1993). In this study, technology is found in the community college and the younger respondents who were observed to be more likely to be comfortable in using technology in accessing information.

Responses of the respondents however, as far as their educational attainments were concerned did not have bearings on their perception of the other dimensions of learning and in readiness to change attitude. In this case, the null hypothesis stating that there is no significant difference in the perception of the respondents on team learning, empowerment, system connection, and provision of leadership is not rejected. Likewise, the hypothesis that there is no significant difference in the 
perception of the respondents on readiness to change attitude is also not rejected. This means that educational attainments of these respondents do not have bearings on their perceptions of team learning, empowerment, system connection, and provision of leadership and readiness to change.

On the other hand, job responsibility in the data is categorized as staff, faculty member, department chair, and administrator. The job responsibility of the respondents were not sources of differentiating opinions considering their perceptions of the various dimensions of a learning organization. These mean score of these at a glance dimensions show diverse responses. However, they are not statistically significant enough as to reject the hypothesis. Thus, the hypothesis that there is no significant difference in the perceptions of the respondents on the various dimensions of learning is not rejected. Likewise, job responsibility is not a source of variance in the opinions of the respondents considering the attitude towards change readiness.

Data shows that except for one dimension of learning organization which is the provision of leadership, there is a significant difference in the opinions between permanent and contractual employees on their perception of the community college as a learning organization.

What is more noteworthy is that the contractual employees show higher mean scores of their perceptions of the dimensions of learning organization compared to the permanent employees. In the Focus Group Discussion (FGD), this finding is validated. The researcher observed and confirmed during discussion that younger generation respondents (mostly contractual employees) seemed to be more idealistic and usually carries a positive outlook and perceptions towards learning organization (February 15, 2016, 6:00p.m.).

On the other hand, attitudes were perceived to have no significant difference between contractual and permanent employees on their response towards readiness to change as shown in the $\mathrm{t}$-values which have not reached the levels of significance. The hypothesis, therefore, is not rejected.

Years of experience was found to be a significant source of differentiating opinions among the respondents considering the seven dimensions of a learning organization thus, the null hypothesis is rejected. The years of experience variable surprisingly revealed that those who have lesser experience with the community college have higher mean scores compared to those who have stayed longer in the institution. Specifically, those respondents with three years and below were more open to the dimensions of a learning organization. 
Years of experience in this study was categorized as 3 years and below, 4-15 years, 16-25 years, and above 25 years. In continuous learning, mean responses are significantly different across the years of experience of the respondents most especially with 3 years \& below ( $M=3.6$, sometimes) which means that they usually experience this dimension in the college and with those who have 4-15 years of experience $(M=2.9$, occasionally) who rated in this dimension very least. For dialogue and inquiry, the mean responses in years of experience were likewise found to be significantly different where three years $\&$ below responded sometimes $(\mathrm{M}=3.83$. $)$ and still observed to be the highest compared to the rest.

The trend that those who are new to the community college rated learning organization were also observed to be the highest in team learning $(\mathrm{M}=4.00$, sometimes); empowerment ( $\mathrm{M}=3.62$, sometimes); system connection ( $\mathrm{M}=3.82$, sometimes); provide leadership ( $M=3.73$, sometimes). Collectively, the respondents with three years of experience $\&$ below perceived significantly higher from the other groups in the existence of all dimensions of a learning organization. In this attitude towards readiness to change, however, years of experience were observed to be higher among those who have experience of above 25 years $(M=2.88$, agree $)$ and those with 4-15 years of experience $(M=2.74$, agree).

Findings of this specific problem of the study have grave implications for the planned change of developing the community college into a learning organization. First, the younger respondents, as well as those who are new to the community college, were more open to the idea of learning organization as seen in their trend of responses. Second, those who are new and are still on contractual basis were also found to be more inclined towards learning organization. This data is rich enough to be considered by the community college for human resource management purposes.

\section{CONCLUSIONS}

The dimensions of the learning organization of this community college in focus were observed to be practiced to a limited extent only. However, the plan to embrace continuous learning, effective communication system, cooperation and empowerment and strategic leadership, can be seen in attitude towards readiness to change.

It was earlier theorized that learning organization as a paradigm should be 
approached holistically. Since, a good learning organization develops the people's positive attitude towards change and further leads to a more conducive learning environment, it is important that the community college seriously consider this holistic approach to develop itself towards being a learning organization. To do so, it is of paramount importance that the community college values its faculty and staff, regarding them as the most important resource to gain competitive advantage and to meet the demands of globalized pressure.

\section{RECOMMENDATIONS}

From the drawn conclusions, the following measures are recommended:

1. That existing policies of the institution be regularly reviewed to address the evolving needs of the college.

2. That faculty and staff development program be substantially budgeted and implemented to promote a good learning environment and fosters employees positive attitude towards change.

\section{LITERATURE CITED}

Acuna, S.T., Gomez, M., \& Juristo, N. (2009). How do personality, team processes and task characteristics relate to job satisfaction and software quality? Information and Software Technology,51 (3), 627-639. http:// dx.doi.org/10.1016/J.infsof.2008.08.006

Alam, M.F. (2009). Learning organization and development of woman managers in Pakistan. Human Resource Development International, 12(1), 105 -114.http://www.tandfonline.com/doi/abs/10.1080/136788608026 38891\#.VuiZl-ak2Ag

Al-Jawazneh, B. E., \& Al-Awawdeh, W. M. (2011). Measuring the degree of the presence of learning organization dimensions at the branches of commercial banks in the governorate 
Asadi, H., Ghorbani, M. H., \& Naderan, M. (2009). The relationship between the learning organization and productivity in iran physical education organization. World Journal of Sport Sciences, 2(3), 160-164. http:// www.ijbssnet.com/journals/Vol_3_No_3

Ayupp, K. \& Perumal, A. (2008). Learning organization: exploring employee perception, The Icfai University Journal of Organizational Behavior, 7 (3), 22-33 https://www.google.com.ph/?gfe_rd=cr\&ei= AannVqO1BsbC8geYvJrQCA\&gws_rd=ssl\#q=Ayupp\%2C+K.\%2C +Perumal $\% 2$ C+A.+\%282008\%29+Learning+Organization:+Exploring + Employee+

Azeem, S.M. (2010). Job satisfaction and organizational commitment among employees in the Sultanate of Oman. Psychology, 1: 295-300. https://www.google.com.ph/?gfe_rd=cr\&ei=uejnVuKUL9LC8gfs4 JmgBQ\&gws_rd=ssl\#q=Azeem\%2C+S.+M.+2010.+Job+satisfaction+ and+organizational+commitment+among+employees+in+the+Sultana te+of+Oman+Psychology\%2C+1:+295-300.

Bernerth, J. (2004). Expanding our understanding of the change message. Human Resource Development Review, Vol. 3 No. 1, pp. 36-52. http:// hrd.sagepub.com/content/3/1/36

Brimeyer, T.M., Perrucci, R., \& Wadsworth, S.M. (2010). Age, tenure, resources for control, and organi-zational commitment*. Social science squarterly, 91: 511-530. https://www.google.com.ph/?gfe_rd= cr\&ei=tXPrVr2TDMWC8AX51ogI\&gws_rd=ssl\#q=Brimeyer $\% 2 \mathrm{C}+$ Perrucci $\% 2 \mathrm{C}+\% 26+$ Wads-worth

Brown, M. \& Cregan, C. (2008). Organizational change cynicism: the role of employee involvement. Human Resource Management, 47(4), 667686.https://www.researchgate.net/publication/246869380_ Organizational_change_cynicism_The_role_of_employee_involvement

Bui, H. \& Baruch, Y. (2010). Creating learning organizations: a systems perspective. The Learning Organization, 17(3), 208-227. http:// mlq.sagepub.com/ content/43/5/515.abstract 
Causon, J. (2004). 'The internal brand: successful cultural change and employee empowerment', Journal of Change Management, vol. 4, no. 4 http://handbook.uts.edu.au/subjects/details/013128.html

Cinches, M. F., Russell, R.L., Borbon, M.L.F., Chavez, J. (2015).

Internationalization of higher education institutions: The Case of Four HEIs in the Philippines. Paper Presented at the15th Annual Conference of Southeast Asian Association of Institutional Research (SEAAIR), Hanoi, Vietnam, September 27-30,, 2015

Choi, M. (2011). Employees' attitudes towards organizational change: A literature review. Human Resource Management, 50(4), 479-500. http://arno.uvt.nl/show.cgi?fid=136204

Creswell, J. W. (2009). Research design: qualitative, quantitative, and mixed methods approaches. London: Sage. https://books.google.com.ph/ books?id=bttwENORfhgC\&dq=Creswell,+J.+W.+\%282009\%29.+ Research+Design:+Qualitative,+Quantitative,+and+Mixed+Methods+ Approaches. + London: + Sage. $\&$ hl $=$ en \&sa $=X \& v e d=0$ ahUKEwji6I7rvsL LAhVBk5QKHaVsB68Q6AEIGzAA

Dirani, K.M. (2009). Measuring the learning organization culture, organizational commitment and job satisfaction in the Lebanese banking sector. Human Resource Development International, 12(2), 189-208.http:// www.sciencedirect.com/science/article/pii/S1877042815012720

Dunham, R.B., Grube, J.A., Gardner, D.G., Cummings, L.L., \& Pierce, J.L. (1989). The development of an attitude toward change instrument. Paper presented at the Academy of Management Annual Meeting, Washington, DC.https://www.aiaee.org/attachments/article 1873/350.pdf

Egan, T., Yang, B., \& Bartlett, K.R. (2004). The effects of organizational learning culture and job satisfaction on motivation to transfer learning and turnover intention. Human Resource Development Quarterly, 15(3), 279-302. http://dx.doi.org/10.1002 
Filstad, C., \& Gottschalk, P. (2011). Becoming a learning organization: the espoused values of police managers from two Norwegian districts. The Learning Organization,18(6), 486-500. http://brage.bibsys.no/ xmlui/bitstream/handle/11250/93408/Filstad\%20Gottschalk\%20 2011\%20LearnOrg_authorversion.pdf?sequence=1

Giessner, S.R. (2011). Is the merger necessary? the interactive effect of perceived necessity and sense of continuity on post-merger identification. Human Relations, 64(8), 1079-1098. https://books.google.com.ph/ books?id=jrp1AwAAQBAJ\&printsec=frontcover\&dq=Giessner

Gil, I., Berenguer, G. \& Cervera A. (2008). The roles of service encounters, service value, and job satisfaction in achieving customer satisfaction in business relationships, Industrial marketing management, 37 (8): 921-939. http://dx.doi.org/10.1016/j.indmarman.2007.06.008

Greenhalgh, T., Robert, G., MacFarlane, F., Bate, P., \& Kyriakidou, O. (2004). Diffusion of innovations in service organizations: systematic review and recommendations. The Milbank Quarterly, 82(4), 581-629. http:// www.ncbi.nlm.nih.gov/pubmed/15595944

Greenwood, R. \& Hinnings, C.R. (1996). Understanding radical organizational change: bringing together the old and the new institutionalism. The Academy of Management Review, 21 (4), 1022-1054. http:// www.jstor.org/stable/259163

Haque (2008). A study on the relationship between the learning organization and organizational readiness for change. Proquest LLC. https:// books .google.com.ph/books?id=Ge4NByjIDm0C\&pg=PA87\&dq= relationship+of+job+responsibilty+on+readiness+to+change+in+the +organization\&hl=en

Jamali, D., \& Yusuf, S. (2009). Learning organizations: diagnosis and measurement in a developing country context the case of Lebanon. The Learning Organization, 15(1).http://www.emerald insight.com /doi/full/10.1108/09696470810842466 
Johnson (2015). Do age and education matter? organizational demography as an influential factor on perceptions of a learning organization in law enforcement. The International Journal of Bahamian Studies, Vol 21, No 1 http://journals.sfu.ca/cob/index.php/files/article/view/250/pdf -23

Kumar, N. \& Idris, K. (2006). An examination of educational institutions' knowledge performance: analysis, implications, and outlines for future research. The Learning Organization, 13(1), 96-117. http:// www.idpublications.org/wp-content/uploads/2014/08/validating-the -dimensions-of-the-learning-organization-questionnaire-dloq-in-the -rwandan-context-.pdf

Lewin, K. (1951). Group decision and social change. In I. L. Newcomb, \& E. L. Hartley, Readings in social psychology. New York: Henry Holt. https://books.google.com.ph/books?id=YU8IpnTnQasC\&pg= PT295\&dq=Lewin,+ K.+\%281951\%29.+Group+decision + and + social+ change.+In+I.+L.+Newcomb,+\%26+E.+L.+Hartley,+Readings+in+ social+psychology\%28pp.+459-473\%29.+New+York:+Henry+Holt. \&hl=en\&sa=X\&ved=0ahUKEwict5KUvsLLAhUGIZQKHbteAacQ6 AEIGzAA\#v=onepage $\& \mathrm{q}=$ Lewin

Marsick, V.J. \& Watkins, K.E. (2003). Demonstrating the value of an organization's learning culture: The Dimensions of Learning Organizations Questionnaire. Advances in Developing Human Resources, pp. 132-151 http://adh.sagepub.com/content/5/2/132. short? $\mathrm{rss}=1 \&$ ssource $=\mathrm{mfc}$

Marsick, V. J. (2009). Toward a unifying framework to support informal learning theory, research and practice. Journal of Workplace Learning, 21(4),265-275.https://www.google.com.ph/?gfe_rd=cr\&ei=U7HnVs O4O87C8 geaoJyoBw\&gws_rd=ssl\#q=Marsick\%2C++V.+J.+\%28 $2009 \% 29$.+Toward+a+unifying+framework+to+support+informal+ learning+theory $\% 2 \mathrm{C}+$ research+and+practice.++Journal+of+ Workplace +Learning\%2C+21+\%284\%29\%2C+265+-+275. 
Madsen, S.R., Miller, D., \& John C.R. (2005). Readiness for organizational change: do organizational commitment and social relationships in the workplace make a difference. Human Resource Development Quarterly, vol. 16, no. 2, pp. 213-233. http://onlinelibrary.wiley.com/doi/10. 1002/hrdq. 1134

McConnell, C.R. (2010). Change can work for you or gainst you: It's your choice. The Health Care Manager, 29(4), 365-374. https://books. google.com.ph/books?id=vDCoCwAAQBAJ\&pg=PA69\&lpg=PA69\& $\mathrm{dq}=$ McConnell,+C.+R.+\%282010\%29.+Change

McHargue, S.K. (2003). Learning for performance in non-profit organizations. Advances in Developing Human Resources, 5(2), 96-204. http://adh.sagepub.com/content/5/2/196.abstract

Miller, D., Madsen, S.R., \& John, C.R. (2006). Readiness for change: Implications on employees' relationship with management, job knowledge and skills, and job demands. Journal of Applied Management and Entrepreneurships, vol. 11, no. 1, pp. 3-16. https://www.questia.com/library/journal/1P3-117677392 1/ readiness-for-change-implications-on-employees-relationship

Moloi, K.C., Gravett, S.J., \& Petersen, N.F. (2009). Globalization and its impact on education with specific reference to education in South Africa. Educational Management Administration and Leadership, 37 (2):2 78 -2 97 http://www.krepublishers.com /02-Journals/JSS/JSS-38-0-000-14-Web/JSS-38-3-000-14-AbstPDF/JSS-38-3-271-14-1548-Naidoo-D-G/JSS-38-3-271-14-1548Naidoo-D-G-Tx\%5B6\%5D.pmd.pdf

Patnaik, B., Beriha, G.S., Mahapatra, S.S., \& Singh, N. (2012). Organizational learning in organizational settings (technical): An Indian Perspective. The Learning Organization, 20(2). https://www.google.com.ph/?gfe_ rd=cr\&ei=vbPnVsXSNszC8gewpZ4I\&gws_rd=ssl\#q=Patnaik\%2C + B. $\% 2 \mathrm{C}+$ Beriha $\% 2 \mathrm{C}+\mathrm{G} .+$ S.\%2C+Mahapatra 
Peach, M., Jimmieson, N.L., \& White, K.M. (2005). Beliefs underlying employee readiness to support a building relocation: a theory of planned behavior perspective. Organization Development Journal, 23,9-22. http://eprints.qut.edu.au/27495/1/c27495.pdf

Rafferty, A.E. \& Simons, R.H. (2006). An examination of the antecedents of readiness for fine-tuning and corporate transformation changes. Journal of Business and Psychology, Vol. 20 No. 3, pp. 325-50. http://espace.library.uq.edu.au/view/UQ: 82108

Saavedra, S. (2013). The mediating effect of organizational variables on the relationship between job satisfaction and turnover intentions. PAGE 10 Journal, Philippine Education for Graduate Education Region 10

Senge, Peter M. (1990). The fifth discipline: The Art \& Practice of the Learning Organization. Doubleday, New York, NY.

Senge, P. M. (1990). The leader's new work: building learning organizations, Sloan Management Review; Fall 1990; 32, 1; ABI/INFORM Global http://sloanreview.mit.edu/article/the-leaders-new-work-building -learning-organizations/

Senge, P. (2006). The fifth discipline: The Art and Practice of the Learning Organizations. New York: Double Day.

Song, J. H., Joo, B. K. B., \& Chermack, T.J. (2009). The dimensions of learning organization questionnaire (DLOQ): A validation study in a Korean context. Human Resource Development Quarterly, 20(1), 43-64. http://dx.doi.org/10.1002/hrdq.20007

Staniforth (1996). Teamworking, or individual working in a team?, team performance management: An International Journal, Vol. 2 Iss: 3, pp.37 - 41 http://www.emeraldinsight.com/doi/ abs/10.1108/13527599610126256 
Tseng, C.C. (2010). The effects of learning organization practices on organizational commitment and effectiveness for small and medium-sized enterprises in Taiwan. Doctoral Dissertation The University of Minesota. https:// www.google.com.ph/?gfe_rd=cr\&ei=U7HnVsO4O87C8geao JyoBw \&gws_rd=ssl\#q=Tse

Wang, X., Yang, B., \& McLean, G.N. (2007). Influence of demographic factors and ownership type upon organizational learning culture in Chinese enterprises. International Journal of Training \& Development, http://dx.doi.org/10.1111/j.1468-2419.2007.00278.x

Watkins, K.E., \& Marsick, V.J. (1993). Sculpting the learning organization lessons in the art and science of systematic change: San Francisco: Jossey-Bass. https://www.google.com.ph/?gfe_rd $=$ cr\&ei $=v b P n V s X S N s z C 8 g e w p Z 4 I \& g w s \_r d=s s l \# q=$ Watkins $\%$ 2C++K.++E.\%2C++\%26++Marsick

Watkins, K. E., \& Marsick, V. J. (1996). In action: creating the learning organization. Alexandria, VA: American Society for Training and Development. https://www. google.com.ph/?gfe_rd=cr\&ei=vbPnV sXSNszC8gewpZ4I\&gws_rd=ssl\#q=Watkins\%2C+K.+E.\%2C +\%26+Marsick\%2C+V.+J.+\%281996\%29.++In+action:+Creating +the+learning+organization. Alexandria $\% 2 \mathrm{C}+\mathrm{VA}:+$ American++Society + for+Training+and+ Development.

Watkins, K.E., \& Marsick, V.J. (1999). Dimensions of learning organization (DLOQ) Warwick, RI: Partners for the Learning Organization. https://www.google.com.ph/?gfe_rd=cr\&ei=XinoVubgE8qI8AWql7 WABQ\&gws_rd=ssl\#q=Watkins\%2C+K.+E.\%2C+\%26+Marsick $\% 2 \mathrm{C}+\mathrm{V} .+\mathrm{J} .+\% 281997 \% 29 .++$ learning+organization+\%28 DLOQ $\% 29+$ Warwick\%2C+RI:+Partners+for+the+Learning+ Organization.

Watkins, K. E., \& Marsick, V. J. (2003). Making learning count! diagnosing the learning culture in organizations thousand oaks, CA: Sage. https://www.google.com.ph/?gfe_rd=cr\&ei=U7HnVsO4O87C8geaoJ yoBw\&gws_rd=ssl\#q=Watkins 
Yang, et al. (2004). The construct of the learning organization: dimensions, measurement, and validation. Human Resource Development Quarterly, 15(1), 31-56. https://www.google.com.ph/?gfe_rd=cr\&ei $=$ XinoVubgE8qI8AWql7WABQ\&gws_rd=ssl\#q=Yang\%2C+et+al.\% $2 \mathrm{C}++\% 282004 \% 29$.+ The+construct+of+the+learning+ organization: + dimensions $\% 2 \mathrm{C}+$ measurement

Yousef, D. A. (2000). Organizational commitment as a mediator of the relationship between Islamic work ethic and attitudes toward organizational change. Human Relations, 53(4), 513-537. https://books.google.com.ph/books?id=JIfFBAAAQBAJ\&pg= PA322\&dq=Yousef,+D.+A.+\%282000\%29.+Organizational +commitment+as+a+mediator+of+the+relationship+between+ Islamic+work+ethic+and+attitudes+toward+organizational+change. +Human+Relations, +53 